\title{
Book Review: The Routledge Handbook of Phenomenology of Agency
}

\author{
Nicola Spano ${ }^{1}$ (D) \\ Published online: 22 February 2022 \\ (c) The Author(s) 2022
}

The Routledge Handbook of Phenomenology of Agency is a new volume in the series Routledge Handbooks in Philosophy, which collects contributions written by leading scholars in both emerging and established fields of philosophical inquiry, aiming to provide accessible yet thorough assessments of problems, themes, thinkers, and recent developments in research.

The editors, Christopher Erhard and Tobias Keiling, state that the motivation for editing this volume originates from the desire, expressed by Terry Horgan, John Tienson, and George Grahman in 2003, to overcome a major philosophical blindspot: the widespread and unfortunate ignorance of the phenomenology of agency in philosophy of mind. Notably, in making this desire their own, Erhard and Keiling embark on an even more challenging task than that envisioned by Horgan, Tienson, and Grahman, for they attempt to cover the manifold meanings that are usually associated with "phenomenology." All of the chapters in the volume are related to at least one of three main senses of the term: an historical sense that is associated with "phenomenology" when the concept is used to refer to the philosophical tradition founded by Edmund Husserl; a methodological sense through which "phenomenology" refers to a certain way of doing philosophy; and an experiential sense, which was the sense intended by Horgan, Tienson, and Grahman, according to which "phenomenology" refers to the "what-it-is-like" of having an experience. Depending on which specific sense is taken into consideration, the development of a phenomenology of agency presents one with different themes, problems, and directions of inquiry. Fully aware of this, Erhard and Keiling point out that "although often taken as self-evident, the relation between the historical and the methodological implications of 'phenomenological' philosophy becomes the more controversial the closer one looks" (p. 1). Furthermore, they note that, although there is clearly a connection between what is initially required by a phenomenological account of agency in the experimental sense and

Research assistant in DFG-Project "Non-object-directed Intentionality: Tendency and Affect".

Nicola Spano

nicola.spano@uni-wuerzburg.de

1 Institute of Philosophy, University of Würzburg, Würzburg, Germany 
the starting point of many accounts of phenomenological method, "to specify this connection is a related, but different task, as is working to this end with the help of authors from the phenomenological tradition" (p. 2). The Routledge Handbook of Phenomenology of Agency, thus, neither presupposes nor implies a univocal way of understanding "phenomenology" and the reader should not assume that this term is used synonymously or equivalently throughout the volume. Rather than settling the question of how precisely phenomenology is to be understood, Erhard and Keiling expect the handbook to stir a discussion of this very question.

Beside promoting debate on the meaning of phenomenology in general and of phenomenology of agency in particular, the editors pursue two further goals with this volume. First, they "wish to portray the richness of phenomenological accounts of human agency" (p. 1). Second, they "want to underline that a phenomenological approach is relevant, if not indispensable in the treatment of fundamental problems in the philosophy of action" (p. 1). In order to achieve these goals, the volume is divided into two parts, each aimed at pursuing one of these stated aims. In Part I, entitled Important Figures: From Brentano to Tengelyi, the contributions to the question of agency made by eminent phenomenologists such as Franz Brentano (discussed by Denis Seron), Edmund Husserl (by Karl Mertens), Martin Heidegger (by Sacha Golob), Max Scheler (by Eugene Kelly), Merleau-Ponty (by Thomas Baldwin), Jean-Paul Sartre (by Simone Neuber), Alfred Schütz (by Michael Barber), Hannah Arendt (by Marieke Borren), Emmanuel Levinas (by Michael L. Morgan), and Paul Ricœur (by Timo Helenius) are discussed at length. The substantial contributions made by lesser-known phenomenologists such as Alexander Pfänder (discussed by both Karl Mertens and Genki Uemura), Edith Stein (by Antonio Calcagno), Adolf Reinach (by Francesca De Vecchi), Dietrich von Hildebrand (by Alessandro Salice), and Hans Reiner (by Christopher Erhard), are also addressed. Last but not least, the phenomenological reflections of three contemporary scholars-Hubert Dreyfus (discussed by Justine F. White), Hermann Schmitz (by Henning Nörenberg), and László Tengelyi (by Tobias Keiling)_receive consideration. The coverage of this vast array of phenomenologists is meant not only to provide a wide and variegated overview of the phenomenology of agency, but also to challenge Uriah Kriegel's recent claim, which gives voice to a widely-held view, that "the golden decade of conative phenomenology [...] arrives only in the French Philosophy in the 1940s" (p. 2). According to Erhard and Keiling, the numerous chapters of Part I show, on the contrary, that there was a "golden era" of conative phenomenology in the early decades of the twentieth century, in particular between the publication of Husserl's Logical Investigations in 1901 and the publication of Heidegger's Being and Time in 1927. In these years, "not only did Husserl work extensively on the notion of action (Handlung) and related lived-experiences such as volitions, strivings, and intentions; many of his early followers developed succinct analyses of the realm of human activity" (p. 2). Importantly, Erhard and Keiling also contend that, by "engaging with more recent discussions and basic questions concerning human agency, the chapters in Part I show that the history of phenomenology is not a mausoleum of dead ideas and thinkers but an occasion for a fruitful dialogue with the past" (p. 2). 
Part II of the volume, entitled Systematic Perspectives, is devoted to the collection of papers by contemporary scholars with different backgrounds, who in their work refer to at least one of the three possible senses of the term "phenomenology" distinguished above. These scholars are Terry Horgan, Martine Nida-Rümelin, David Woodruff Smith, Robert Hanna, Shaun Gallagher, Galen Strawson, Roberta De Monticelli, John J. Drummond, Günter Figal, and Uriah Kriegel. The first half of the chapters in this second part are focused on general issues in phenomenology of agency, such as the problem of determining the fundamental structures of and the necessary conditions for action. The second half of the chapters are focused instead on specific aspects of human agency, such as freedom, rational action, deliberation, choice, involuntariness, and morality. Through this rich diversification of topics, the goal of showing the significance, not to say the necessity, of a phenomenological approach is further pursued. But to what extent is The Routledge Handbook of Phenomenology of Agency successful in achieving this and its other stated goals?

In my view, the volume convincingly achieves the overall aim of the series, which is to provide indispensable reference tools for students and researchers seeking a comprehensive overview of new and exciting topics in philosophy. The inclusion of a broad range of thinkers is particularly significant to achieving this end, since the editors are fundamentally right in claiming that "it cannot do to concentrate on merely one author as representative of 'phenomenology' in the historical and the methodological sense" (p. 2) (and, arguably, in the experimental sense). It is simply not possible to take for granted that the different interests, ideas, and methods of phenomenologists are somehow convergent. Erhard and Keiling mention for example Husserl's practice of identifying the essential (eidetic) structures of action in association with the methodological preference for the so-called first-person perspective, and note that arguments would be needed to show why any phenomenological methodology should proceed in the same manner. Another example could be the performance of "intentional analyses," which is fundamental for Husserl and all the members of the Munich and Göttingen circles of phenomenology, but no longer characterizes, at least not in the sense it had for Husserl and his followers, Heidegger's "hermeneutics of facticity." The same applies to the notion of "intentionality" in analytic philosophy of mind. As discussed in one of chapters of the volume, namely "The Phenomenology of Rational Agency" by Roberta De Monticelli, it is an open question whether and how this notion, which is usually understood as "aboutness," relates to the notion of "intentionality" as "directedness to," or "awareness of intentional objects" inherited from Husserl. Or, to give an example more closely related to the experience of agency, one could argue that, whereas the analytic philosophers interested in exploring the "what-it-is-like" of agency are mainly interested in the deliberative case of action, continental phenomenologists, especially post-Husserlians, focus more upon the case of non-deliberative action, in which the agent acts without pursing in a rational way any represented goal. The volume gives the student ample opportunity to familiarize herself with this and many other thematical, conceptual, and methodological differences, motivating at the same time the researcher to reflect on them, so as to clarify whether the phenomenological research on agency should and could pursue the same path. Whatever the final answer to the question of the meaning of phenomenology might be, there is no 
doubt that the volume presses this very question by portraying a great richness of phenomenological accounts.

The task in which the The Routledge Handbook of Phenomenology of Agency is the most successful, however, is, arguably, in framing a serious discussion among diverse and even conflicting theories of action. Indeed, the volume is not a mere collage of philosophers and their schools or lines of thought, but rather a unitary collection that shows how manifold philosophical positions can enter into fruitful dialogue with one another. This achievement is made possible by the work of the editors, who give unity to the collected articles by indicating, at the end of each chapter, the related topics within the volume and by suggesting additional readings. Importantly, the promotion of dialogue among different philosophical positions also fulfils the crucial goal of proving the relevance, if not even the necessity, of a phenomenological approach to the problem of agency. The contributors, including those who focus on historical figures in the phenomenological tradition, expend a great effort to achieving this end. For example, in his article "Dietrich von Hildebrand on the will and intentional agency," Alessandro Salice critically discusses, in light of Hildebrand's phenomenological analysis, Frankfurt's idea that the notion of the will can be reduced to that of desire and, thus, does not point to a genuine psychological category. The outcome of Salice's discussion is the following insight, which deserves to be reported in its entirety since it concisely states a possible reason for the necessity of a phenomenology of agency:

[t]he concept of "to want" is ambiguous and thus in need of an analysis. But then, which analysis should be preferred? There are reasons to believe that an analysis able to capture the fine-grained (phenomenological) differences between our conative experiences is preferable to any analysis that waters down all those differences. In fact, it is only on the basis of a phenomenologically sound theory of desires, (different forms of) willing, intentions that one can ascertain which of those sentences is compatible with which conative notion. Only this way can disambiguation be acquired. But if this is correct, it strongly suggests that the best way to achieve disambiguation of our psychological concepts is by means of phenomenology and, crucially, by its core methodological idea that everything is what it is (and not something else). (p. 74)

Similar considerations can be found in Cristopher Erhard's article "The Varieties of Activity: Reiner's Contribution." On Erhard's view, Reiner's variety thesis, "according to which human agency is not restricted to rational-intentional 'deeds,' but covers various forms or ways of activity, all of which are experientially manifest to us in at least a minimal way" (p. 79) provides a more nuanced solution to the so-called "problem of action" that is broadly discussed in contemporary analytic philosophy. This problem consists "in finding the 'mark' of the rational-cumintentional 'deeds' of persons, which are contrasted with things 'merely happening' to them" (p. 80). However, whereas scholars in analytic philosophy tend to assume that all events in which an agent can be involved are either deliberative actions or passive occurrences, Reiner overcomes such a dichotomous view and "draws a more nuanced picture that allows for numerous intermediate "stages"” (p. 80). Also in this 
case, thus, a phenomenological account of agency proves to be more fine-grained, that is, more sensitive to the differences among conative phenomena, and it is therefore better able to clarify them. These two examples are by no means the only ones, for each of the 27 chapters of the handbook actively engages with the task of showing why and how phenomenology can make a substantial contribution to our philosophical understanding of agency, both with respect to the general problem of determining the fundamental structures of and the necessary conditions for action, and with respect to more specific aspects, such as freedom, rational action, and morality. Unfortunately, I cannot discuss here the insights of each specific study and must leave it to the reader to explore them.

Before concluding this brief review, I would like to focus upon another goal of the volume that is surely important for the readers of Husserl Studies, namely the demonstration that Husserl and his contemporaries preside over a "golden era" of conative phenomenology. While the examples given above indicate that this is the case with Hildebrand and Reiner, the other chapters of the handbook prove that this is true also for Pfänder, Stein, Reinach, and Husserl himself. The reflection on action performed by the father of phenomenology is specifically addressed by Karl Mertens in the chapter "Phenomenology of Willing in Pfänder and Husserl," but it is also discussed at length by Roberta De Monticelli in her chapter "The Phenomenology of Rational Agency" and by John J. Drummond in "Acting, Choosing, and Deliberating." The reader should note that these contributions are not mere introductory guides, but rather state-of-the-art works that prove the richness and the valuableness of Husserl's account. Furthermore, the thesis that a well-developed conative phenomenology can be found already in Husserl is corroborated by the recent publication of the Husserliana edition Studien zur Struktur des Bewusstseins. The third volume of this new edition is entitled "Wille und Handlung" and consists of more than 500 pages devoted to an in-depth analysis of volition and action. There is, thus, no doubt that Husserl's philosophical interest goes beyond epistemology and value theory and includes also the field of action. It is now the task of Husserlian scholars to explore the depth of this field.

In conclusion, The Routledge Handbook of Phenomenology of Agency is a highly valuable resource for any student or researcher who is interested in exploring this vast and promising venue of research and I strongly recommend it.

On behalf of all authors, the corresponding author states that there is no conflict of interest.

Funding Research funded by the Deutsche Forschungsgemeinschaft (DFG, German Research Foundation) - Project-ID 446126658. Open Access funding enabled and organized by Project DEAL.

Open Access This article is licensed under a Creative Commons Attribution 4.0 International License, which permits use, sharing, adaptation, distribution and reproduction in any medium or format, as long as you give appropriate credit to the original author(s) and the source, provide a link to the Creative Commons licence, and indicate if changes were made. The images or other third party material in this article are included in the article's Creative Commons licence, unless indicated otherwise in a credit line to the material. If material is not included in the article's Creative Commons licence and your intended use is not permitted by statutory regulation or exceeds the permitted use, you will need to obtain permission 
directly from the copyright holder. To view a copy of this licence, visit http://creativecommons.org/licen ses/by/4.0/.

\section{Reference}

Erhard, C., \& Keiling, T. (Ed.). (2021). The Routledge Handbook of Phenomenology of Agency. New York, NY: Routledge.

Publisher's Note Springer Nature remains neutral with regard to jurisdictional claims in published maps and institutional affiliations. 